\title{
A systematic review and meta-analysis of laparoscopic versus robotic rectal surgery with primary anastomosis
}

\author{
Mateusz Rubinkiewicz, Jan Witowski, Karolina Zbroja, Kamil Rozmus, Julia Krzywoń, Katarzyna Truszkiewicz \\ 2nd Department of General Surgery, Faculty of Medicine, Jagiellonian University Medical College, Krakow, Poland; \\ Head of the Department: Prof. Andrzej Matyja MD PhD
}

Article history: Received: 21.10.2019 Accepted: 05.11.2019 Published: 05.11.2019

ABSTRACT: $\quad$ Purpose: Rectal cancer is one of the most common malignancies of the gastrointestinal tract. The gold standard method is surgical resection. The approach to rectal cancer is still controversial. Nowadays, robotic approach gains popularity in comparison to traditional laparoscopy. However, there is a lack of studies assessing rectal resections with primary anastomosis.

Methods: We performed a systematic review and meta-analysis according to the PRISMA guidelines. The primary outcomes of interest were morbidity and short-term complications.

Results: An initial reference search yielded 1250 articles. Finally, we chose six studies covering 1580 patients that we included in the quantitative analysis. In our study, we demonstrated that laparoscopic and robotic surgery are non-inferior to one another in terms of morbidity ( $\mathrm{RR}=1.195 \% \mathrm{Cl}$ : 0.89-1.39), major complication rate $(\mathrm{RR}=1.01,95 \% \mathrm{Cl}: 0.60-1.69)$ or length of hospitalization ( $\mathrm{MD}=0.1595 \% \mathrm{Cl}:-0.60-0.90)$. The latter has a slight advantage in the quality of mesorectal excision $(\mathrm{RD}=-0.19,95 \% \mathrm{Cl}:-0.35--0.03 . \mathrm{I} 2=69 \%)$ and anastomotic leakage rate $(\mathrm{OR}=2.25,95 \% \mathrm{Cl}: 1.23-4.09, \mathrm{I} 2=0 \%)$.

Conclusion: In certain cases, Robotic Surgery provides better quality of resected specimen and lower leakage ratio; nevertheless due to heterogeneity the results are uncertain. There is a substantial need for large randomized controlled studies.

KEYWORDS: $\quad$ laparoscopic, meta-analysis, rectal cancer, robotic, systematic review

\section{ABBREVIATIONS}

APR - also abdominoperineal resections

IS - intersphincteric rectal resection

NOS - Newcastle-Ottawa Scale

PRISMA - Preferred Reporting Items for Systematic Reviews and Meta-Analyses

TME - total mesorectal excision

\section{INTRODUCTION}

Rectal cancer is one of the most common malignancies of the gastrointestinal tract. It affects approximately 1.8 million people all over the world every year. Surgery remains a gold standard of rectal cancer treatment [1]. Among many factors, proper removal of the mesorectal fascia is the most important one for the procedure to be successful $[2,3]$. It is proved that the quality of mesorectal excision affects long-term survival. Difficulties in mesorectal excision appear especially in low rectal cancer (located $<5 \mathrm{~cm}$ from the anal verge) [4]. This is one of a few reasons why surgeons often prefer abdomino-perineal resection, which substantially diminishes patients' quality of life [5]. Since Prof. Rullier introduced intersphincteric rectal resection (IS), new frontiers have appeared for sphinter-sparing surgery [6]. Introduction of modern techniques, including laparoscopy or robotic surgery, provided better visualization of the operative field, which should result in a better quality of mesorectal excision. Despite advances in the development of technical equipment, benefits of laparoscopic technique in comparison to open approach are still unambiguous [7-9]. On the other hand, robotic surgery is cost-consuming, and proved to be non-superior to laparoscopy in terms of oncological outcomes in different branches of surgery [10]. As most of the patients strongly prefer sphincter-saving surgery, which provides substantially bet- ter quality of life, efforts in that direction should be made. Therefore, we designed a study to compare laparoscopic and robotic techniques in sphinter-saving rectal surgery.

\section{METHODS}

\section{Search strategy}

We conducted a literature search strictly following Preferred Reporting Items for Systematic Reviews and Meta-Analyses (PRISMA) guidelines [11], MOOSE consensus statement and included EMBASE, Medline, and The Cochrane Library databases [12]. Potentially relevant studies were identified by searching for the following terms: "laparoscopy", "laparoscopic", "minimally invasive", "robotic", "robot", "rectal surgery", "sphincter-saving", and their combinations with Boolean "AND" and "OR" operators. We included full texts in English; there were no date restrictions. Our last search was performed on January 1, 2019. The full search strategy is available in Supplementary File 1 . The systematic review was registered, and its protocol published in the International Prospective Register of Systematic Reviews (PROSPERO) under registration number CRD42019119951 before the start of this study.

\section{Study selection}

Results of the initial search were screened independently by two teams with three reviewers in each team. Studies containing data comparing morbidity between patients undergoing pure laparoscopic and robotic sphincter-saving resection for rectal cancer were considered eligible for inclusion. Studies related to national registries, reviews, and animal studies were excluded. Both nonrandomized and randomized studies were eligible as long as they matched the inclusion criteria. 


\section{$\mathbf{1 , 2 5 0}$ references identified for screening}

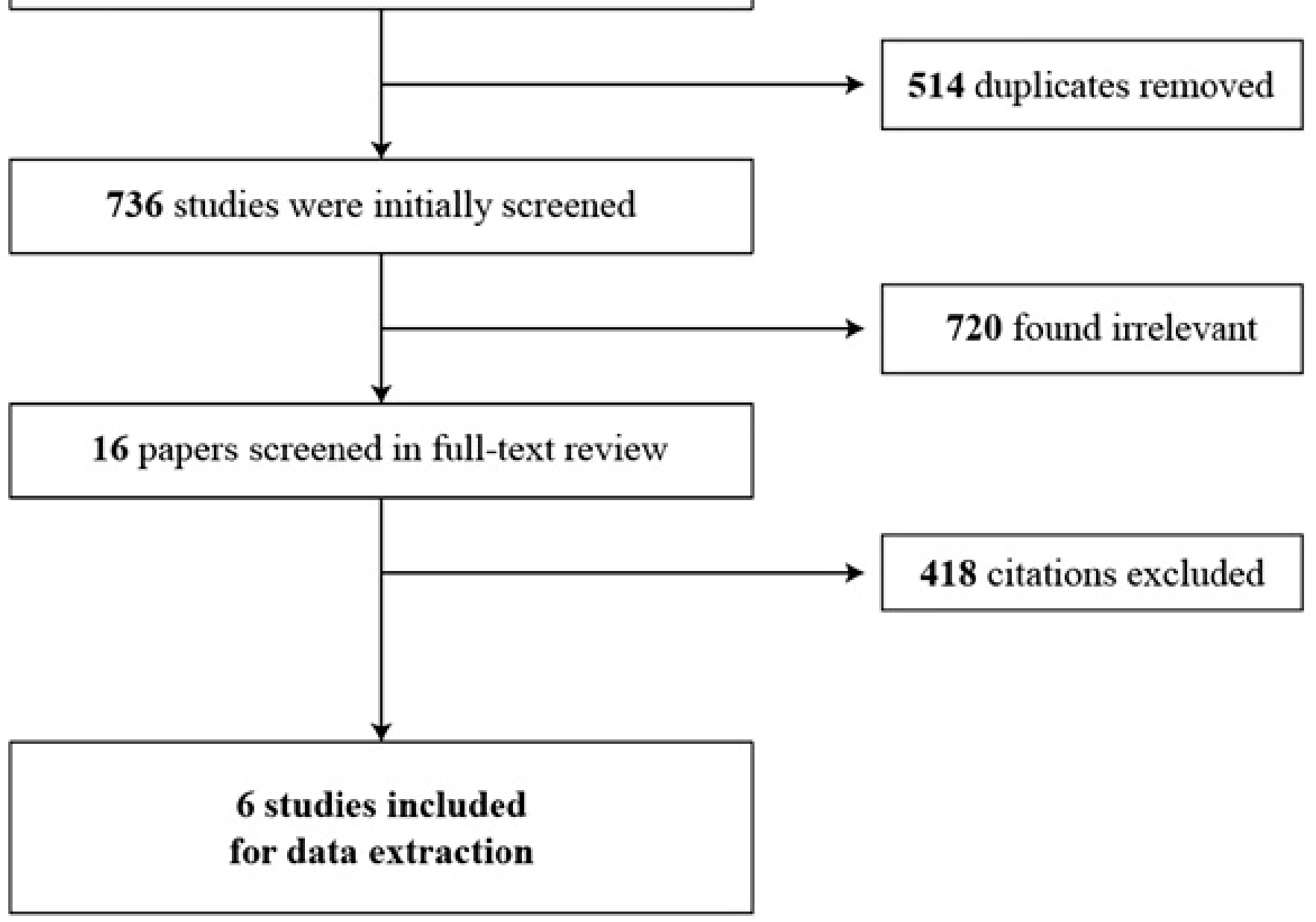

Fig. 1. PRISMA flowchart of the study selection process.

\section{Data extraction and outcome measures}

Extracted outcomes of this systematic review were major morbidity, operative time, blood loss, conversion rate, ileostomy rate, distal and circumferential resection margin, harvested lymph nodes, reoperation rate, postoperative mortality, anastomotic leakage, haemorrhage, abscesses, surgical site infection and length of hospital stay. Data on the type of study, number of patients enrolled, patients' age and sex, type of surgery, tumor TNM staging and preoperative chemotherapy were also extracted. When the Clavien-Dindo scale was used, complications rated as Clavien-Dindo grade 3 and higher were considered major [13].

\section{Statistical analysis}

The analysis was performed using RevMan 5.3 (freeware from The Cochrane Collaboration) and $\mathrm{R}$ version 3.4 .3 with meta package [14]. Statistical heterogeneity and inconsistency were measured using the Cochran's Q test and I2, respectively. Qualitative outcomes from individual studies were analyzed to assess individual and pooled risk ratios (RR) with pertinent $95 \%$ confidence intervals (CI) favoring laparoscopic over robotic sphincter-saving resection for rectal cancer and by means of the random-effects method. When appropriate, mean and standard deviation (SD) were calculated from medians and interquartile ranges using a method pro- posed by Hozo et al. [15] Weighted mean differences with 95\% CI are presented for quantitative variables using the inverse variance random-effects method. Statistical significance was observed at the two-tailed 0.05 level for hypothesis and 0.10 level for heterogeneity testing, while unadjusted $P$ values were reported accordingly.

\section{Quality assessment}

The quality of non-randomized studies was evaluated with the Newcastle-Ottawa Scale (NOS), which consists of three factors: patient selection, comparability of the study groups, and assessment of outcomes [18]. A score ranging from 0 to 9 is assigned to each study, and those that achieve a score of 6 or greater are considered of high quality.

\section{RESULTS}

\section{Study identification}

Fig. 1. presents the PRISMA flowchart of the study selection process containing reasons for study exclusion. A total of 1,250 articles were retrieved through the initial search. After removing 514 duplicates, 736 studies were screened by their titles and abstract for further analysis. A total of 720 manuscripts did not match the 
Tab. I. Characteristics of included studies. ND no data

\begin{tabular}{|c|c|c|c|c|c|c|c|}
\hline STUDY ID & YEAR & COUNTRY & \#LAP/ROBOTIC (N) & $\begin{array}{l}\text { N E O A D J U V A N T } \\
\text { TREATMENT } \\
\text { ROBOTIC }\end{array}$ & $\begin{array}{l}\text { T3-T4 STAGE } \\
\text { ROBOTIC }\end{array}$ & LAP/ & NOS QUALITY SCORE \\
\hline Erguner et al. & 2013 & Turkey & $37 / 27$ & $21.6 \% / 14.8 \%$ & $10.8 \% / 3.7 \%$ & & 8 \\
\hline Serin et al. & 2015 & Turkey & $65 / 14$ & $100 \% / 100 \%$ & $100 \% / 100 \%$ & & 7 \\
\hline Kim et al. & 2016 & Korea & $486 / 533$ & $12.6 \% / 32.3 \%$ & ND & & 8 \\
\hline Colombo et al. & 2016 & France & $60 / 60$ & $65 \% / 78.3 \%$ & $53.3 \% / 81.7 \%$ & & 7 \\
\hline Valverde et al. & 2017 & France & $65 / 65$ & $44.6 \% / 53.8 \%$ & $60 \% / 49.2 \%$ & & 7 \\
\hline Sugoor et al. & 2018 & India & $84 / 84$ & $65.5 \% / 67.9 \%$ & $75 \% / 78.6 \%$ & & 8 \\
\hline
\end{tabular}

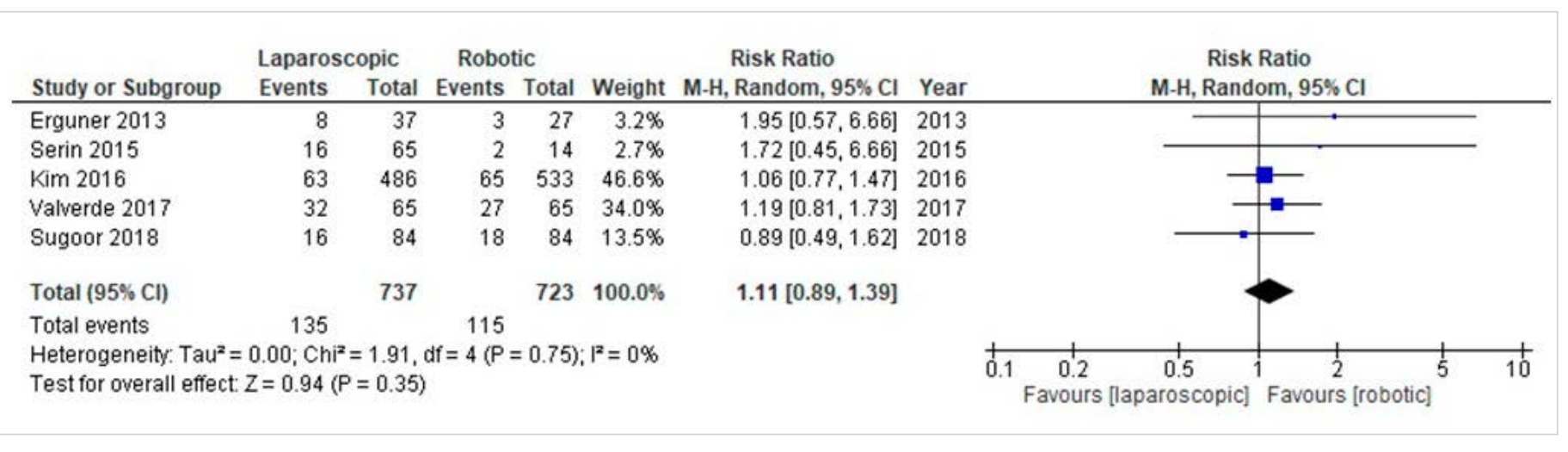

Fig. 2. Pooled estimates of overall morbidity for laparoscopic versus robotic sphincter-saving rectal resections. $\mathrm{Cl}$-confidence interval, $\mathrm{df}-\mathrm{degrees}$ of freedom, $\mathrm{MH}-\mathrm{Mantel}-\mathrm{Haenszel}$.

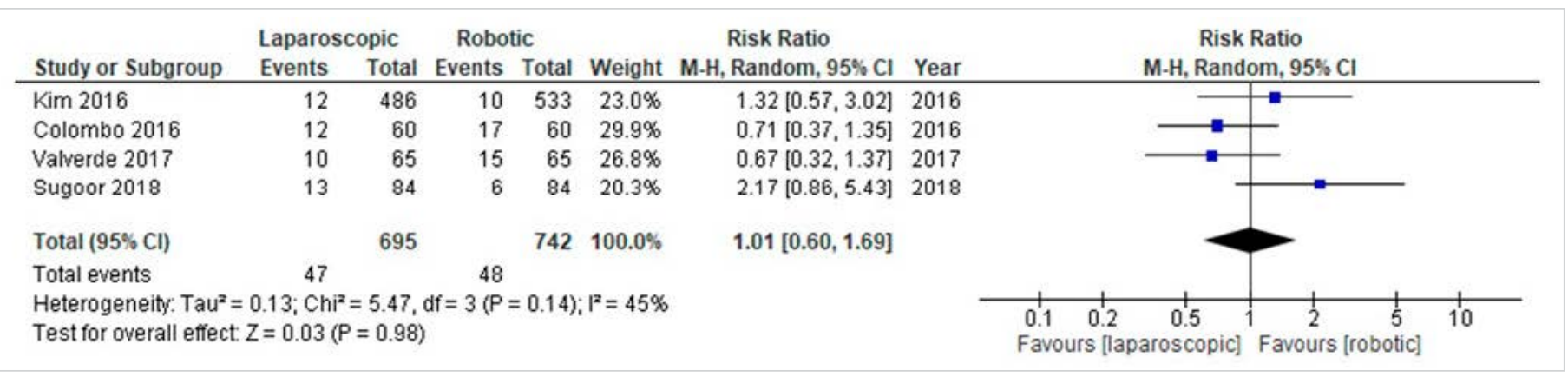

Fig. 3. Pooled estimates of major morbidity for laparoscopic versus robotic sphincter-saving rectal resections. $\mathrm{Cl}$-confidence interval, $\mathrm{df}-\mathrm{degrees}$ of freedom, $\mathrm{MH}-\mathrm{Mantel}$-Haenszel.

review criteria and 16 full-text articles were screened for eligibility and of these, six were finally included for data extraction and pooling analysis.

\section{Characteristics of included studies}

Characteristics of a total of 1,580 patients from 6 included studies are presented in Tab. I. There were no randomized trials matching eligibility criteria. In all included studies, their quality was rated as high (six and higher by assessment using the NOS scale).

\section{Morbidity (overall, major, mortality)}

Five studies reported on overall morbidity. Pooled analysis (Fig. 2.) as well as individual studies showed no statistically significant differences between laparoscopic and robotic groups, with $\mathrm{RR}=1.1,95 \%$ CI: $0.89-1.39, \mathrm{P}$ for effect $=0.35$.

Similarly, groups did not differ in terms of major complication rate (Fig. 3.) or postoperative mortality (Fig. 4.), where pooled analy- sis showed $R R=1.01,95 \%$ CI: $0.60-1.69$ and $R D=-0.00,95 \%$ CI: $-0.00-0-00$, respectively.

\section{Specific complications}

Five out of six studies had data reporting on anastomotic leakage occurrence. Robotic surgery was found to be associated with reduced anastomotic leakage rate: $\mathrm{OR}=2.25,95 \% \mathrm{CI}: 1.23-4.09$, $\mathrm{I} 2=0 \%$ (Fig. 5).

There were no significant differences between groups in terms of hemorrhage, abscess and surgical site infection rate. Heterogeneity in all pooled analyses was low.

\section{Completeness of mesorectal excision}

Three studies reported on mesorectal excision completion. Pooling analysis revealed that robotic surgery was slightly superior, with $\mathrm{RD}=-0.19,95 \% \mathrm{CI}:-0.35--0.03$. However, heterogeneity was moderately high with $\mathrm{I} 2=69 \%, \mathrm{P}=0.04$ (Fig. 6.). 


\begin{tabular}{|c|c|c|c|c|c|c|c|c|}
\hline \multirow[b]{2}{*}{ Study or Subgroup } & \multicolumn{2}{|c|}{ Laparoscopic } & \multicolumn{2}{|c|}{ Robotic } & \multicolumn{3}{|c|}{ Risk Difference } & \multirow{2}{*}{$\begin{array}{l}\text { Risk Difference } \\
\text { M-H, Random, } 95 \% \mathrm{Cl}\end{array}$} \\
\hline & Events & Total & Events & Total & Weight & M-H, Random, $95 \% \mathrm{Cl}$ & Year & \\
\hline Erguner 2013 & 0 & 37 & 0 & 27 & $0.4 \%$ & $0.00[-0.06,0.06]$ & 2013 & \\
\hline Colombo 2016 & 0 & 60 & 0 & 60 & $1.4 \%$ & $0.00[-0.03,0.03]$ & 2016 & \\
\hline Kim 2016 & 0 & 486 & 0 & 533 & $94.8 \%$ & $0.00[-0.00,0.00]$ & 2016 & \\
\hline Valverde 2017 & 0 & 65 & 1 & 65 & $0.8 \%$ & $-0.02[-0.06,0.03]$ & 2017 & \\
\hline Sugoor 2018 & 0 & 84 & 0 & 84 & $2.7 \%$ & $0.00[-0.02,0.02]$ & 2018 & \\
\hline Total $(95 \% \mathrm{CI})$ & & 732 & & 769 & $100.0 \%$ & $-0.00[-0.00,0.00]$ & & \\
\hline Total events & 0 & & 1 & & & & & \\
\hline \multicolumn{8}{|c|}{$\begin{array}{l}\text { Heterogeneity: } \operatorname{Tau}^{2}=0.00 ; \mathrm{Chi}^{2}=0.92, \mathrm{df}=4(P=0.92) ; \mathrm{I}^{2}=0 \% \\
\text { Test for overall effect: } Z=0.07(P=0.95)\end{array}$} & $\begin{array}{ccccc}-0.05 & -0.025 & 0 & 0.025 & 0.05 \\
\text { Favours [laparoscopic] } & \text { Favours [robotic] }\end{array}$ \\
\hline
\end{tabular}

Fig. 4. Pooled estimates of postoperative mortality for laparoscopic versus robotic sphincter-saving rectal resections. $\mathrm{Cl}-\mathrm{confidence} \mathrm{interval,} \mathrm{df}-\mathrm{degrees}$ of freedom, $\mathrm{MH}-$ Mantel-Haenszel.

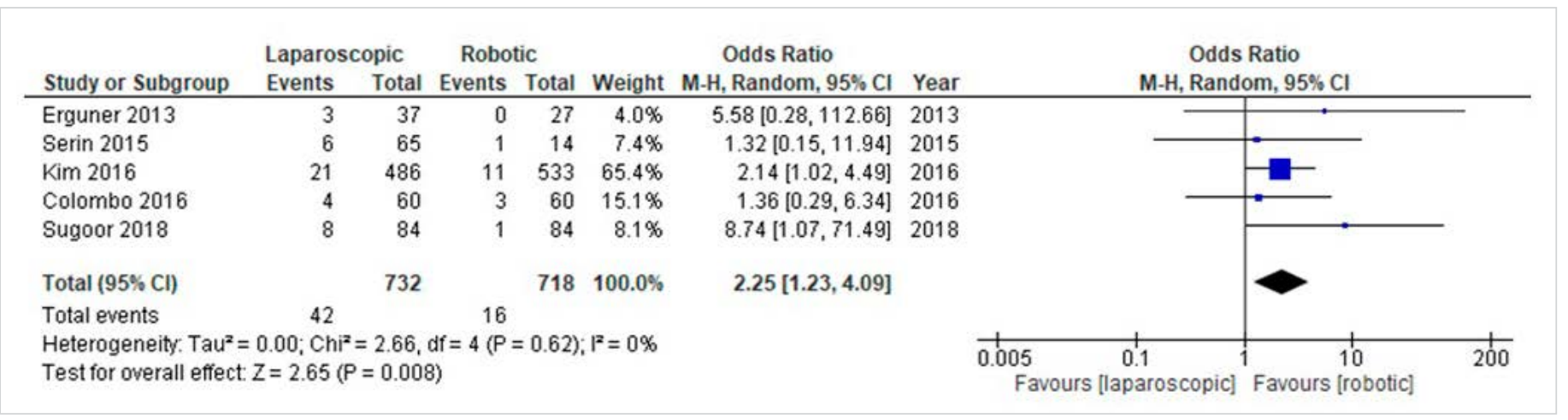

Fig. 5. Pooled estimates of anastomotic leakage for laparoscopic versus robotic sphincter-saving rectal resections. $\mathrm{Cl}-$ confidence interval, $\mathrm{df}-\mathrm{deg}$ rees of freedom, $\mathrm{MH}-\mathrm{Mantel}-\mathrm{Haenszel}$.

\section{Blood loss and operative time}

Data on blood loss and operative time were reported on in four and six studies, respectively. In both outcomes, we did not pool the results because of very high heterogeneity (I $2=87 \%$ for blood loss, $\mathrm{I} 2=90 \%$ for operative time; $\mathrm{P}<0.0001)$. Sensitivity analysis did not reveal a source of this situation.

\section{Length of hospital stay}

There were no significant differences between groups in terms of length of hospital stay, with $\mathrm{MD}=0.15,95 \% \mathrm{CI}$ : $-0.60-0.90$, $\mathrm{P}$ for effect $=0.70, \mathrm{I} 2=29 \%$ (Fig. 7.).

\section{Long-term survival}

Only one study (Kim et al.) reported long-term results, presenting data on 3-year overall and disease-free survival: $94.4 \%$ vs. $94.6 \%$ in case of overall survival and $83.1 \%$ vs. $82.2 \%$ for disease-free survival (laparoscopic versus robotic, respectively). It was not possible to perform a pooled analysis for this outcome.

\section{DISCUSSION}

In our study, which is to our best knowledge the first meta-analysis concerning only sphincter-saving surgery, we demonstrated that laparoscopic and robotic surgery are non-inferior to one another in most aspects. However, robotic surgery has slight advantages in terms of quality of mesorectal excision and anastomotic leakage rate over laparoscopic surgery. Our review also shows that the evidence is still very sparse and with high heterogeneity.
Since Heald introduced the concept of total mesorectal excision (TME), it became a gold standard of rectal cancer treatment, and it revolutionized the overall and disease-free survival. It has been proved recently that the quality of mesorectal excision influences directly long-term treatment outcomes [21]. The discussion whether minimally invasive techniques are suitable for TME is still open. Laparoscopic surgery failed to be non-inferior to open approach in two large randomized control trials (RCT): ACOSOG and ALACART $[7,22]$. However, meta-analysis by Pędziwiatr et al. proved that laparoscopic surgery is as good as open approach [23]. We have to remember that the development of classic laparoscopy is unlikely to progress. Therefore, we need alternatives in the field of minimally invasive techniques, as transanal TME (taTME) or robotic TME $[4,24]$. In our study, robotic surgery allowed to retrieve better quality of surgical specimen regarding the plane of mesorectal dissection, although these results have to be interpreted with some uncertainty due to moderately high heterogeneity. Still, this stays in contrary with a recent study by Jones et al., who compared all available comparative studies and one RCT [25]. In their meta-analysis authors were not able to prove superiority of oncological quality of the procedure. However, they mentioned some advantages of robotic approach, such as lower risk of conversion to an open procedure and shorter time to pass flatus [25]. Earlier meta-analysis by Xiong et al. revealed additionally lower positive rate of CRM, which is crucial for good oncological outcome [26]. On the contrary, a recently published network metaanalysis, assessing three different minimally invasive techniques: laparoscopic, robotic and transanal TME has not found significant differences between them [27]. As revealed in a study performed by Kitz et al., the quality of mesorectal excision has direct influence on local recurrence rate after total mesorectal excision due to rectal cancer [3]. 


\begin{tabular}{|c|c|c|c|c|c|c|c|c|c|}
\hline \multirow[b]{2}{*}{ Study or Subgroup } & \multicolumn{2}{|c|}{ Laparoscopic } & \multicolumn{2}{|c|}{ Robotic } & \multirow[b]{2}{*}{ Weight } & \multirow{2}{*}{$\begin{array}{l}\text { Risk Difference } \\
\text { M- } \mathrm{H}, \text { Random, } 95 \% \mathrm{Cl}\end{array}$} & \multirow[b]{2}{*}{ Year } & \multirow{2}{*}{\multicolumn{2}{|c|}{$\begin{array}{c}\text { Risk Difference } \\
\text { M-H, Random, } 95 \% \mathrm{Cl}\end{array}$}} \\
\hline & Events & Total & Events & Total & & & & & \\
\hline Erguner 2013 & 12 & 37 & 19 & 27 & $24.6 \%$ & $-0.38[-0.61,-0.15]$ & 2013 & $\longrightarrow$ & \\
\hline Serin 2015 & 52 & 65 & 14 & 14 & $37.0 \%$ & $-0.20[-0.33,-0.07]$ & 2015 & & \\
\hline Valverde 2017 & 53 & 65 & 57 & 65 & $38.4 \%$ & $-0.06[-0.19,0.06]$ & 2017 & & \\
\hline Total $(95 \% \mathrm{CI})$ & & 167 & & 106 & $100.0 \%$ & $-0.19[-0.35,-0.03]$ & & & \\
\hline Total events & 117 & & 90 & & & & & & \\
\hline \multicolumn{8}{|c|}{$\begin{array}{l}\text { Heterogeneity: } \text { Tau }^{2}=0.01 ; \mathrm{Chi}^{2}=6.38, \mathrm{df}=2(\mathrm{P}=0.04) ; \mathrm{I}^{2}=69 \% \\
\text { Test for overall effect: } Z=2.34(P=0.02)\end{array}$} & $\begin{array}{cc}-1 \\
-0.5 \\
\text { Favours [robotic] }\end{array}$ & \begin{tabular}{|cc} 
& 1 \\
0 & 0.5 \\
Favours [laparoscopic]
\end{tabular} \\
\hline
\end{tabular}

Fig. 6. Pooled estimates of completeness of mesorectal excision for laparoscopic versus robotic sphincter-saving rectal resections. $\mathrm{Cl}-$ confidence interval, $\mathrm{df}-\mathrm{degrees}$ of freedom, $\mathrm{MH}-$ Mantel-Haenszel.

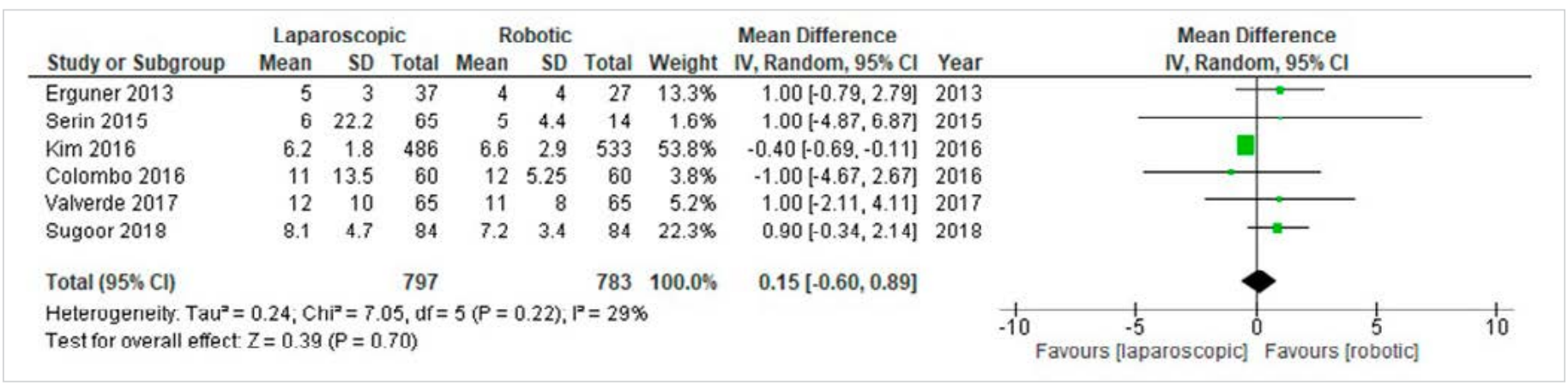

Fig. 7. Pooled estimates of length of hospital stay for laparoscopic versus robotic sphincter-saving rectal resections. $\mathrm{Cl}-$ confidence interval, $\mathrm{df}-$ degrees of freedom, $\mathrm{MH}-$ Mantel-Haenszel.

What is important, all of the aforementioned meta-analyses include studies assessing also abdominoperineal resections (APR), which in our opinion may create bias. During APR there are no anastomoses to be done, and this fact strongly interferes with the reported complication rate. Moreover, nowadays the number of sphincter-saving procedures is increasing due to poor patient acceptation and diminished quality of life after APR [28]. Therefore, we decided to perform a meta-analysis including only studies with sphincter-saving procedures, e.g. ultralow TME or intersphincteric resection, instead of APR.

Our study has some obvious limitations. At first, none of the included studies assessed functional outcomes and quality of life after sphincter-saving procedure, what is of utter importance for patient self-esteem. Current literature proves that most patients after sphincter saving procedures develop minor to major low anterior resection syndrome [5]. We were also not able to pool

\section{REFERENCES}

1. Glynne-Jones R., Wyrwicz L. Tiret E., et al.: Rectal cancer: ESMO Clinical Practice Guidelines for diagnosis, treatment and follow-upt. Ann. Oncol., 2017; 28(suppl_4): iv22-iv40.

2. Quirke P., Morris E.: Reporting colorectal cancer. Histopathology, 2007; 50(1): 103-112.

3. Kitz J., Fokas E., Beissbarth T. et al.: Association of Plane of Total Mesorectal Excision With Prognosis of Rectal Cancer: Secondary Analysis of the CAO/ ARO/AIO-04 Phase 3 Randomized Clinical Trial. JAMA Surg., 2018: e181607.

4. Rubinkiewicz M., Czerwińska A., Zarzycki P. et al.: Comparison of Short-Term Clinical and Pathological Outcomes after Transanal versus Laparoscopic Total Mesorectal Excision for Low Anterior Rectal Resection Due to Rectal Cancer: A Systematic Review with Meta-Analysis. J. Clin. Med., 2018; 7(11): 448.

5. Rubinkiewicz M., Zarzycki P., Czerwińska A. et al.: A quest for sphincter-saving surgery in ultralow rectal tumours-a single-centre cohort study. World J. Surg. Oncol., 2018; 16(1): 218. results for multiple outcomes due to high heterogeneity, and our results suggesting more complete mesorectal excision in robotic group can still be doubted due to moderate heterogeneity. Next, all included studies were observational. There are only few available RCTs, and none of them met the inclusion criteria due to APR presence $[10,29]$. Finally, even though all of the included studies were rated as high-quality using the NOS scale, they still do not provide decisive, high-grade results.

\section{CONCLUSIONS}

The results of the study come with remaining uncertainty due to moderate to high heterogeneity in some outcomes. However, in certain cases, Robotic TME provided better quality of resected specimen and lower leakage ratio. There is substantial need for large randomized controlled studies.
6. Rullier E., Zerbib F., Laurent C. et al.: Intersphincteric resection with excision of internal anal sphincter for conservative treatment of very low rectal cancer. Dis. Colon Rectum, 1999; 42(9): 1168-1175.

7. Fleshman J., Branda M., Sargent D.J. et al.: Effect of Laparoscopic-Assisted Resection vs Open Resection of Stage II or III Rectal Cancer on Pathologic Outcomes: The ACOSOG Z6051 Randomized Clinical Trial. JAMA, 2015; 314(13): 1346-1355.

8. Abbas S.K., Yelika S.B., You K. et al.: jo. Tech Coloproctol, 2017; 21(3): 237-240.

9. Małczak P., Mizera M., Torbicz G. et al.: Is the laparoscopic approach for rectal cancer superior to open surgery? A systematic review and meta-analysis on short-term surgical outcomes. Videosurgery Other Miniinvasive Tech., 2018; 13(2): 129-140.

10. Jayne D., Pigazzi A., Marshall H. et al.: Effect of Robotic-Assisted vs Conventional Laparoscopic Surgery on Risk of Conversion to Open Laparotomy Among Patients Undergoing Resection for Rectal Cancer. JAMA, 2017; 318(16): 1569. 
11. Moher D., Liberati A., TetzlaffJ. et al.: Preferred Reporting Items for Systematic Reviews and Meta-Analyses: The PRISMA Statement. PLoS Med., 2009; 6(7): e1000097.

12. Stroup D.F., Berlin J.A., Morton S.C. et al.: Meta-analysis of observational studies in epidemiology: a proposal for reporting. Meta-analysis Of Observational Studies in Epidemiology (MOOSE) group. JAMA, 2000; 283(15): 2008-2012.

13. Clavien P.A., Barkun J., de Oliveira M.L. et al.: The Clavien-Dindo classification of surgical complications: five-year experience. Ann. Surg., 2009; 250(2): 187-196.

14. Schwarzer G., Carpenter J.R., Rücker G.: Meta-analysis with R, Springer 2015

15. Hozo S.P., Djulbegovic B., Hozo I.: Estimating the mean and variance from the median, range, and the size of a sample. BMC Med. Res. Methodol., 2005; 5(1): 13.

16. IntHout J., Ioannidis J.P.A., Rovers M.M., Goeman J.J.: Plea for routinely presenting prediction intervals in meta-analysis. BMJ Open, 2016; 6(7): e010247.

17. Higgins J.P.T., Thompson S.G., Spiegelhalter D.J.: A re-evaluation of random-effects meta-analysis. J. R. Stat. Soc. Ser. A. Stat. Soc., 2009; 172(1): 137-159.

18. Wells G., Shea B., O'Connell J., Robertson J. et al.: The Newcastle-Ottawa Scale (NOS) for assessing the quality of nonrandomised studies in meta-analysis, 2011.

19. Egger M., Smith G.D., Schneider M., Minder C.: Bias in meta-analysis detected by a simple, graphical test. Bmj, 1997; 315(7109): 629-634.

20. Duval S., Tweedie R.: Trim and fill: A simple funnel-plot-based method of testing and adjusting for publication bias in meta-analysis. Biometrics, 2000; 56(2): 455-463.

21. Fleshman J., Branda M.E., Sargent D.J. et al.: Disease-free Survival and Local Recurrence for Laparoscopic Resection Compared With Open Resection of Stage II to III Rectal Cancer. Ann. Surg., 2018; 1.
22. Stevenson A.R., Solomon M.J., Lumley J.W. et al.: Effect of Laparoscopic-Assisted Resection vs Open Resection on Pathological Outcomes in Rectal Cancer: The ALaCaRT Randomized Clinical Trial. JAMA, 2015; 314(13): 1356-1363.

23. Pedziwiatr M., Małczak P., Mizera M. et al.: There is no difference in outcome between laparoscopic and open surgery for rectal cancer: a systematic review and meta-analysis on short- and long-term oncologic outcomes. Tech Coloproctol, 2017; 21(8): 595-604.

24. Rubinkiewicz M., Nowakowski M., Wierdak M. et al.: Transanal total mesorectal excision for low rectal cancer: a case-matched study comparing TaTME versus standard laparoscopic TME. Cancer Manag. Res., 2018; 10: 5239-5245.

25. Jones K., Qassem M.G., Sains P. et al.: Robotic total meso-rectal excision for rectal cancer: A systematic review following the publication of the ROLARR trial. World J. Gastrointest. Oncol., 2018; 10(11): 449-464.

26. Xiong B., Ma L., Huang W. et al.: Robotic Versus Laparoscopic Total Mesorectal Excision for Rectal Cancer: a Meta-analysis of Eight Studies.

27. Rausa E., Bianco F., Kelly M.E. et al.: Systemic review and network meta-analysis comparing minimal surgical techniques for rectal cancer: quality of total mesorectum excision, pathological, surgical, and oncological outcomes. J. Surg. Oncol., 2019.

28. Rubinkiewicz M., Zarzycki P., Czerwińska A. et al.: A quest for sphincter-saving surgery in ultralow rectal tumours-a single-centre cohort study. World J. Surg. Oncol., 2018; 16(1): 218.

29. Kim M.J., Park S.C., Park J.W. et al.: Robot-assisted Versus Laparoscopic Surgery for Rectal Cancer. Ann. Surg., 2018; 267(2): 243-251.

Liczba słów: $2890 \quad$ Liczba stron: $7 \quad$ Tabele: $1 \quad$ Ryciny: $7 \quad$ Piśmiennictwo: 29

DOI: $\quad 10.5604 / 01.3001 .0013 .5549$

Table of content: https://ppch.pl/issue/12552

Copyright: Copyright @ 2020 Fundacja Polski Przegląd Chirurgiczny. Published by Index Copernicus Sp. z o. o. All rights reserved.

Competing interests: The authors declare that they have no competing interests.

The content of the journal „Polish Journal of Surgery” is circulated on the basis of the Open Access which means free and

- limitless access to scientific data.

This material is available under the Creative Commons - Attribution 4.0 GB. The full terms of this license are available on:

http://creativecommons.org/licenses/by-nc-sa/4.0/legalcode

Corresponding author: Mateusz Rubinkiewicz, MD, PhD; 2nd Department of General Surgery, Faculty of Medicine, Jagiellonian University Medical College, Kopernika 21 Street, 31-501 Krakow, Poland; Phone: +48 511503997; E-mail: mateusz.rubinkiewicz@uj.edu.pl

Cite this article as: Rubinkiewicz M., Witowski J., Zbroja K., Rozmus K., Krzywon J., Truszkiewicz K.: A systematic review and meta-analysis of laparoscopic versus robotic rectal surgery with primary anastomosis; Pol Przegl Chir 2020: 92 (1): 5-11 
